International Journal of Instruction e-ISSN: 1308-1470 • www.e-iji.net
Received: $24 / 07 / 2019$

Revision: 20/03/2020

Accepted: 09/04/2020

OnlineFirst:05/07/2020

\title{
Students' Self-Efficacy Beliefs and TOEIC Achievements in the Vietnamese Context
}

\section{Nguyen Xuan Hong}

MA.,Industrial University of Ho Chi Minh City, Vietnam, nguyenxuanhong@iuh.edu.vn

\section{Nga Thi Tuyet Phan}

PhD., Corresponding author, Industrial University of Ho Chi Minh City, Vietnam, ngaphan2004@gmail.com

This paper draws on self-efficacy questionnaire data collected at the beginning and end of the TOEIC course, TOEIC scores and focus group discussions data from participating students at a technical university in Vietnam. While the quantitative data reveal positive effects in terms of TOEIC self-efficacy, the qualitative data show how changes in self-efficacy were moderated by the way students cognitively processed self-efficacy information. Results indicate there was a positive change in students' self-efficacy after joining the course. Self-efficacy was an important variable of students' TOEIC achievements and affected their achievement positively. Mastery experiences appeared to be the most influential source of TOEIC self-efficacy. Results are discussed as they relate to previous research and recommendations are made to include the development of selfefficacy in TOEIC instruction. The paper highlights that by targeting sources of self-efficacy, teachers can empower students with control over their own TOEIC ability development. Generally, TOEIC courses should promote learning environments that foster important sources of self-efficacy. Besides, course material and feedback should be delivered in a way that levels of self-efficacy are increased.

Keywords: TOEIC achievement, self-efficacy, EFL context, achievement, learning

\section{INTRODUCTION}

In academic literature, perceived self-efficacy is defined as "people's judgments of their capabilities to organize and execute courses of action required to attain designated types of performances" (Bandura, 1997, p. 391). Perceived self-efficacy may affect one's selection of activities and subsequent efforts put forth. People's persistence in accomplishing the given tasks involved in the activities varies in their intellectual performances depending on the strength of their perceived self-efficacy. In the recent

Citation: Hong, N. X., \& Phan, N. T. T. (2020). Students' Self-Efficacy Beliefs and TOEIC Achievements in the Vietnamese Context. International Journal of Instruction, 13(4), 67-86. https://doi.org/10.29333/iji.2020.1345a 
years, given the important role of perceived self-efficacy in mediating students' efforts and subsequent learning outcomes (Bandura, 1997; GençKuluşaklı \& Aydın, 2016), there have been a growing number of studies investigating students' self-efficacy in the ESL/EFL contexts. In addition, due to the popularity of TOEIC (Test of English for International Communication) as a measure of English language proficiency throughout the world (Geddes, 2016; ETS, 2015), many studies have examined students' attitudes to TOEIC, their preparation for TOEIC tests or the impacts of the tests (Geddes, 2016; Hsieh, 2017). However, a few researchers have conducted studies examining how second/foreign language self-efficacy influences students' TOEIC achievements, which influential sources of self-efficacy information students rely on to build their TOEIC self-efficacy, and whether their TOEIC self-efficacy beliefs improve after joining a preparation course. In addition, most of the available research is quantitative in nature (e.g. Chen, 2007; Taguchi, 2015) while Phan (2016) and Wyatt (2014) suggested that because self-efficacy itself is complex, the combination of quantitative and qualitative methods is necessary. Mixed methods, according to Wyatt (2014), can potentially lead to useful outcomes such as "providing insights into the relative impacts of different components of the education program and supporting course evaluation and design processes" (p. 183).Therefore, there is a need for more studies employed mixed methods in investigating this issue.

In light of Bandura's (1997) self-efficacy theory, the purposes of this study are threefold: a) to examine whether there is a positive change in students' self-efficacy after participating in the TOEIC preparation course; b) to examine the influence of foreign language self-efficacy beliefs (i.e., self-efficacy for performing TOEIC Listening and Reading tasks) on foreign language learning outcomes (i.e., TOEIC scores) and c) to understand which sources of self-efficacy information students rely on to build their self-efficacy beliefs. Understanding the relationship between students' self-efficacy and TOEIC achievements and the impacts of sources of self-efficacy information on students' self-efficacy can ultimately help such students gain better scores on their exams. Teachers and educators may also gain useful knowledge to improve their training programs and teaching materials. To accomplish the three purposes of the study, this research employed a mixed methodology utilizing a survey instrument and semistructured interview questions. The study sought to answer the following questions.

1. Is there a positive change in students' self-efficacy after participating in the TOEIC course?

2. What is the relationship between students' self-efficacy beliefs and their TOEIC scores?

3. What sources of information do the students rely on to build their self-efficacy beliefs?

\section{LITERATURE REVIEW}

\section{Self-Efficacy Beliefs}

According to Zhang and Ardasheva (2019), the motivational construct that is most related to EFL learners' perceptions of their own abilities to learn or accomplish certain 
learning tasks is self-efficacy beliefs. As noted by Tschannen-Moran et al. (1998), selfefficacy is a facet of Social Cognitive Theory which rests on the idea that environmental factors, personal factors and behaviors are constantly influencing one another (Bandura, 1997, p. 6).The strength of each of the three factors - personal factors, environment and behaviour - is not equal but varies depending on individuals and situations. Selfefficacy judgments in a given contexts are possibly influenced by learners' past performances (Mastery Experience), experiences with others' performances (Vicarious Experience), persuasion from significant others (Social Persuasion), and physiological and emotional changes (Psycho-physiological State). Bandura stated that mastery experiences are the most powerful source of self-efficacy information compared to other sources. Tschannen-Moran et al. (1998) also stated that mastery experiences and emotional states associated with these experiences most directly influence self-efficacy beliefs (p. 229). Palmer (2006; 2011) suggested another type of mastery experiences, cognitive mastery of content and skills, which is distinctive from enactive mastery experiences (Bandura, 1997) since it does not involve doing something but rather about understanding something (p. 339). The significant role of cognitive mastery experiences has been confirmed in several studies (e.g. Morris \& Usher, 2011; Morris, 2010). Compared to other sources of self-efficacy information, physiological states have been often suggested to be the weakest source (Iaochite \& Souza, 2014; Morris \& Usher, 2011).

Self-efficacy possesses some specific features that make it distinguishable from other concepts. First, self-efficacy is one's self-perception of competence, not one's actual level of competence (Tschannen-Moran et al., 1998, p. 211). Second, self-efficacy should be "a judgment of capability" (Bandura, 1997, p. 43) and a "forward-looking capability" (Klassen et al., 2011, p. 26), not an intention to carry out a task. Bandura stressed that items measuring self-efficacy beliefs should include can rather than will. Third, self-efficacy is different from other self-conceptions (Schunk, Pintrich, \& Meece, 2008; Tschannen-Moran et al., 1998). For example, self-concept beliefs refer to current ability while self-efficacy beliefs refer to future-oriented capability (Bandura, 1997). Self-esteem is a "global, affective reaction or evaluation" that people can have about themselves, for example, "I feel happy when learning English." Self-perception of competence is a "cognitive judgment of personal skills and abilities" to accomplish certain tasks (Schunk et al., 2008, p. 58, italics in original), for example, "I can learn English". As Schunk et al. (2008) noted, like self-competence, self-efficacy differs from self-esteem in that it is a cognitive evaluation of capabilities and is domain specific. However, unlike self-competence, self-efficacy is task- and situation specific (Tschannen-Moran et al., 1998). It includes a judgment of having necessary behavioral actions or cognitive skills to accomplish the tasks (Schunk et al., 2008). This perceived self-efficacy is one's belief about one's ability to coordinate skills to accomplish tasks in different conditions. It is more than "judgments of motor acts" (Bandura, 1997, p. 37) or "a summation of decontextualized perceived efficacy for sub-skills" (p. 38). 


\section{The TOEIC Reading and Listening Test}

TOEIC is a standardized test that is used as a tool to measure people's English skills to understand, use and communicate in English. Many businesses, corporations, government agencies and educational institutions throughout the world have used the TOEIC test to judge if a person is qualified to become or to remain one of their workers, or to be promoted. Educational Testing Service (ETS) developed the TOEIC test and is the official organization that administers the test. The TOEIC Listening and Reading Test is a 2 hour multiple-choice test consisting of 200 questions. Test candidates must have strong vocabulary and grammar skills as well as being able to read and listen to English fluently. They are expected to quickly understand and respond to the workplace situations presented with in the test. The test is claimed to be an accurate reflection of what test candidates will encounter in the international working environment. Test takers have 45 minutes to complete 100 multiple choice questions for Listening. There are 4 different sections, each with a different kind of stimulus. Reading is also 100 multiple choice questions which should be completed in 75 minutes. Reading consists of 3 different sections, each with a different kind of stimulus. After the test, each candidate receives independent scores for Listening and Reading comprehension on a scale from 5 to 495 points. The total score adds up to a scale from 10 to 990 points (ETS, 2015). According to ETS (2007), students achieving under 250 points are basic beginners and able to satisfy immediate survival needs. Those getting from 255 to 400 are at elementary level and have functional but limited proficiency. They are able to maintain very simple face-to-face conversations on familiar topics. Immediate level learners earning from 405 to 600 can initiate and maintain predictable face-to-face conversations and satisfy limited social demands.

Preparation for the TOEIC test is important. It is advised that students should practice their English skills daily by immersing themselves in the target language frequently and in many ways. Currently, there exist a lot of learning materials on the Internet and from bookstores. Regarding preparation time, research shows different amount of preparation time for different kinds of learners. For example, 200-level learners might expect a 100point gain after just 100 hours of instruction, but 500-level learners might need 250 or 300 hours to gain 100 points. Researchers also suggest that intensive study, e.g., classes meeting every day for two or three hours, is likely to be more beneficial than classes that meet only once a week for an hour or two. If students are required to take the test before there is significant improvement, it is likely that they will be disappointed and discouraged when their scores are not as high as they expect (Childs, 2002).

\section{Review of Previous Studies on Students' Self-Efficacy Beliefs and TOEIC Achievements}

Although numerous studies have conducted in the field of EFL/ESL self-efficacy beliefs, little attention has been paid to students' TOEIC self-efficacy. A search for English language publications which investigate TOEIC self-efficacy in peer-reviewed educational research journals between 2007 and 2018 yielded only a limited number of articles and dissertation. Findings of important studies are briefly reported as follows. 
All researchers in the review agreed with the idea that self-efficacy played a positive role in enhancing students' TOEIC scores. The students who had strong self-efficacy beliefs achieved better on their TOEIC scores. Chen (2007) employed a survey questionnaire consisting of 21 questions to examine students' TOEIC listening selfefficacy and their learning outcomes. The researcher compared students' grades at the beginning and at the end of the semester. What Chen (2007) found out is that selfefficacious students were likely to gain higher TOEIC students than students with a low sense of self-efficacy. Similarly, some researchers, e.g. Harada (2016), Oh (2012), Taguchi (2015) and Toyama (2015), examined the impact of self-efficacy on students' achievement and the effectiveness of TOEIC classes. They all employed questionnaires and analysed the scores of students' TOEIC placement tests and end-of-course tests. The researchers concluded that participants' self-efficacy positively correlated to their TOEIC scores.

The findings of these studies indicated a positive relationship between self-efficacy and performance, which are in line with the most of the findings in other research domains such as EFL/ESL, math and education in general (Meera \& Jumana, 2016; Meral, Colak, Zereyak, 2012; Siriparp, 2015; Raoof, Tan \& Chan, 2012). However, none of these studies investigated both TOEIC reading and listening self-efficacy. In addition, some studies, e.g. Taguchi (2015), had a limited number of items investigating selfefficacy in the questionnaires and these items neither reflected the task-specific nature nor related to future-oriented capability of self-efficacy beliefs (e.g. I know basic vocabulary to some extent; I am good at memorizing vocabulary). Therefore, these limitations may have led to their statistically less significant impact.

In relation to studies investigating changes in TOEIC self-efficacy and which sources of self-efficacy information led to such changes, among the limited number of studies that examined students' TOEIC self-efficacy beliefs in the review, only two investigated sources of self-efficacy. Details of these two studies are presented below.

Todaka (2016) conducted a mixed method study with 197 Japanese university students to examine whether instruction that focused on sources of self-efficacy could help EFL learners improve their English listening skills and enhance their self-efficacy. Students were divided into 3 groups according to their placement test scores: introductory, intermediate and advanced class. They were taught phonetic features, meta-cognitive strategies, suprasegmental features, learning strategies, and shadow training. Thirty six students from three groups above were given monthly guidance counseling sessions (mastery experiences and social persuasion) in which they discussed how well they had enjoyed improving their listening skills (mastery experiences and vicarious experiences) and how they had felt about the weekly emails (affective states). Tokada found out that the self-efficacy scores of intermediate and advanced students in the control group significantly worsened, whereas those of students in the introductory group increased. Many introductory students, who had difficulty understanding simple utterances by native English speakers during the onset of the study, were able to demonstrate improved understanding during the semester. This, in turn, brought them a sense of achievement which helped them to maintain a high level of perceived self-efficacy 
throughout the academic year.

Burrows (2016) explored the effects that past experiences seem to have on current levels of students' TOEIC reading self-efficacy. The author delivered a questionnaire consisting of 50 items to 322 first and second year students at a Japanese university. Findings indicated that students who were self-efficacious in junior high also exhibited similar levels of self-efficacy in high school and university. The study implied that in their studies, providing learners with early positive experiences of success (mastery experiences) that might help to boost self-efficacy can also help them to be more selfefficacious later. Teaching reading strategies and giving learners authentic opportunities to read would help learners gain a stronger sense of self-efficacy. Offering students support and praise for tasks completed also helped on the verbal persuasion source. Coaching students strategies to manage their foreign language anxiety (affective states) reduced the detrimental effects of that component on self-efficacy.

Generally, findings of studies in the review confirmed a positive relationship between self-efficacy and performance. In addition, when students at elementary level in the EFL classroom were provided with achievable activities (mastery experiences) and opportunities to cultivate their self- efficacy (social persuasion combined with vicarious experiences and affective states), a stronger sense of self-efficacy would be engendered. Owing to the limited number of studies in the field of TOEIC self-efficacy, a study designed to examine the mediation role of self-efficacy on TOEIC performance and the interplay of self-efficacy information is thus desired in an Asian context. In addition to the importance of examining the role of self-efficacy on TOEIC performance and the inter-relationship of sources of self-efficacy information, a self-efficacy measure that conforms to Bandura's $(1997,2006)$ guidelines is needed in measuring students' TOEIC self-efficacy. In creating self-efficacy instruments, Bong (2006) mentioned the caution not to confuse between self-efficacy and other constructs such as self-confidence and self-esteem in order to ensure the task and context specific nature of self-efficacy. This present study is, therefore, a step towards addressing these gaps by investigating how Vietnamese students' sense of self-efficacy beliefs mediated their TOEIC achievements and how sources of self-efficacy information were processed by means of a mixed method approach.

\section{METHOD}

The present study took the form of a mixed method study. Using questionnaires (selfefficacy scales) to gauge the changes in self-efficacy at the beginning and at the end of the research can possibly provide a safe environment to approach sensitive topics (e.g. rating self-efficacy in learning TOEIC), especially in the Vietnamese context where participants have a concern for loss of face and public image (Tran, 2006). In addition, because "self-efficacy beliefs are themselves complex, meaningful interpretations" (Wheatley, 2005, p. 559, italics in original), qualitative methods can provide clear examples of how participants internalize efficacy-relevant information in a complex way. 


\section{Research context}

The study took place in one of the biggest technical universities in the South of Vietnam. The university offers a range of educational services to students, university degrees, in-service degrees to vocational certificates. At the university where the study was conducted, the students who are non-English majors are offered two TOEIC preparation courses in the second and third semester based on their placement test results. Students who score under 250 (introductory level) and 350 (elementary level) will register for the first and second course respectively. Each TOEIC preparation course lasts 45 periods in approximately 15 weeks. Students meet once a week for two hours and ten minutes. The textbook used for the course is TNT TOEIC: Basic course. The course features (a) review of basic grammar, (b) a review of listening and reading skills, c) reading and listening practice and (d) exam skills. The target TOEIC scores at the end of the first and second course are 250 and 350 respectively. Students are encouraged to obtain 450 by graduation as the university requirement. All freshmen at the university before joining the TOEIC courses learnt basic grammar, reading and listening lessons in junior and senior high school.

Participants included 94 Vietnamese first-year students from 3 different classes majoring in Accounting, Electronic Engineering, Machinery Engineering, Food Technology, and Chemical Engineering. They took the introductory TOEIC preparation course, aiming at achieving 250 scores.

\section{Material and Procedures}

The questionnaire: Creswell (2012) stated that a questionnaire is a widely used and useful instrument for collecting survey information, providing structured, often numerical data being able to be administered without the presence of the researcher and often being comparatively straightforward to analyze. Leedy and Ormrod (2005) highlighted that a close-ended question in the questionnaire provides limited choices to answer and uses simple, clear, and unambiguous language. In this study, the questionnaire consisted of 2 main sections. Section 1 had 7 question items asking participants about TOEIC learning background. Section 2 was designed to measure students' TOEIC Reading and Listening Comprehension Self-efficacy. There were 24 items in the scale based on a Likert scale ranging from 1 (not at all self-efficacious) to 5 (extremely self-efficacious). The reliability of self-efficacy items for the Reading section and the Listening was found 0.916 and 0.922 respectively.

The test: The pre-test and post-test used in the present study were TOEIC mock tests. The mock tests were taken from IIG's previous test booklets. IIG's test procedures and regulations were applied to the mock tests. According to ETS (2015), the TOEIC Listening and Reading test uses the KR-20 reliability index which assesses the extent to which all items measure the same construct. ETS claims that the reliability of the TOEIC Listening and Reading section scores across all forms from their samples has been approximately 0.90 and up. Regarding validity, ETS states that the TOEIC Listening and Reading test includes a variety of important English language tests. 
Focus group discussions: This research instrument is generally regarded as facilitating participation and interpersonal communication and to encourage a supportive environment (Thomas, 2008), which aligns broadly with certain Vietnamese cultural values. Because participating students in the study had never participated in any research, the stressful feeling probably produced by their first-time participation in research was hopefully lessened by peers' presence (Marshall and Rossman, 2011, p. 149). In the discussions, students were invited to talk about their perceptions of factors relating to the TOEIC preparation class and English learning. The main purpose of the focus group discussions was to provide more information which helped to understand if there was a positive change in students' self-efficacy beliefs when they finished the course, whether self-efficacy and TOEIC achievement correlated at the end of the course, and which sources of students' TOEIC self-efficacy information were important. Each focus group discussion lasted approximately 30 minutes and it was audio recorded. There were 9 focus group discussions in total. Transcript of each discussion was sent back to participants via Zalo chat application to change or add content. Members of each focus group discussion were put in a separate chat room so that they could help to validate possible changes in data. In reality, all participants agreed with the content of the original transcripts. The data received from participants were confidential, anonymised and shared between the researcher and each group of participants only.

Procedures: The questionnaire was distributed to participating students at two different points in time, at the outset and at the end of the TOEIC preparation course. The researcher made sure that students filled out the survey before they took the test. The participants were informed that their personal information would remain confidential and only used for a research purpose before being distributed the questionnaire. One hundred and twenty five students responded to the questionnaire when it was first distributed. After the result of the pre-test was released, from a pool of 125 students, 94 students were grouped into 3 introductory classes for the present study because their scores were below 250. Ninety four students filled out the same questionnaire and sat a TOEIC post-test 4 months later. Participating students were invited to focus group discussions conducted immediately after they finished the second TOEIC mock test at the end of the training course.

Data analysis: The quantitative data analysis was made by using the Statistical Package for Social Sciences (SPSS) version 20.0. Differences in self-efficacy scores at the beginning and end of the course were analysed using a Paired-samples t-test. Pearson correlation was conducted to examine the relationship between the students' selfefficacy and TOEIC proficiency at the end of the course.

To analyse qualitative data, I used an inductive coding process (Creswell, 2012) and thematic analysis (Braun \& Clarke, 2006). I started analysing data from each focus group discussion and then compared and contrasted the codes, themes and categories across the nine discussions. I read through each transcript of a discussion. I looked for words, phrases, sentences, or whole paragraphs that related to my specific concern, for example, factors affecting their TOEIC English learning. I searched, cut and pasted chunks of data related to this concern then I started coding. Initially, my codes were 
participants' actual words, phrases or my summary of their ideas. I listed all the codes in the margin. I did not code every sentence because I was unable to process too many codes (Creswell, 2012). I grouped similar codes together, reduced overlapping or redundant codes and ended up with a manageable number of codes. Each major category now consisted of several sub-categories. After I had the categories and subcategories for each group (see table 1), I reviewed and collated them with those of other group discussions. I ended up with the final codes which help answer the research question concerning with what sources of self-efficacy information the students relied on to build up their self-efficacy.

Table 1

Coding Example

\begin{tabular}{ll}
\hline Sources of self-efficacy & Group 1 \\
\hline Mastery experiences & $\begin{array}{l}\text { Self-learn test taking tips, master grammatical exercises; have } \\
\text { good/poor grades on listening tasks; have more right/wrong } \\
\text { answers }\end{array}$ \\
\hline Vicarious experiences & Watch friends doing tasks successfully \\
\hline Social persuasion & $\begin{array}{l}\text { Receiving friends' feedback, teachers' encouragement, feedback, } \\
\text { and evaluation }\end{array}$ \\
\hline Affective states & feel excited, comfortable in the classroom \\
\hline
\end{tabular}

\section{FINDINGS}

\section{Students' self-efficacy before and after the TOEIC preparation course}

Results from a Paired-samples t-test are given in Table 2. The mean rating for selfefficacy before and after the course the course was 2.1330 and 2.5226 respectively. The differences were statistically significant. The results indicate that students' self-efficacy increased slightly after they participated in the course. There was a positive change in students' self-efficacy after joining the course. However, the students' self-efficacy remained at a low level at around 2.5.

Data from focus group discussion provided more information. The researcher invited 4 groups to answer the question: "Do you think your self-efficacy increased after the course?" All students agreed that their TOEIC self-efficacy beliefs improved after the course. They never sat any TOEIC tests or took any TOEIC courses, and "did not have any test taking tips" at high school. Therefore, they were not self-efficacious in doing the TOEIC pre-test. Most students said after the course they were somewhat selfefficacious in "understand[ing] simple sentences", "short paragraphs" or "short, simple spoken exchanges" and got more correct answers compared to what they did previously. However, when it came to the understanding and mastery of complex grammatical constructions and uncommon vocabulary, participating students stated that they "needed to practice more" and "would like to receive more intellectual support from [their] lecturers". Most of them shared that their self-efficacy dropped significantly when listening to "long spoken exchanges", reading "double passages" or when "difficult vocabulary or grammar is present". This somewhat explained why students' self- 
efficacy stayed at a low level at around 2.5 although their self-efficacy changed positively.

The relationship between students' self-efficacy beliefs and their TOEIC scores at the end of the course

In Table 3, positive correlation was found between students' sense of self-efficacy and their TOEIC scores at the end of the course though the correlation was not very strong. The result reveals that the higher their sense of self-efficacy was, the better scores the students achieved in doing the TOEIC post-test and/or those who scored higher in the test appear to have stronger sense of self-efficacy beliefs. In other words, perceived selfefficacy predicted students' performance. Self-efficacy was an important variable of students' TOEIC achievement and affected their achievement positively.

Qualitative data seemed to support quantitative data. In answering the researcher's question, "Do you think that you will perform better in the coming post-test?" It appears that during the discussion, most students reported higher levels of self-efficacy and believed they would do the post-test successfully. For example, one student in group 3 said:

I'm pretty confident now . . I I had so much trouble with listening previously. It was so hard for me. I was very worried! But now, I will pass the test for sure.

Another student in group 2 also reported his improved self-efficacy which was the result of improved scores:

Know what, I could get up to 35 correct answers for the listening section and 45 for the reading one. Unbelievable! I never thought I could do that. I'm confident that my score will be better if I keep trying. I will pass the upcoming test.

Table 2

Self-Efficacy Scores Before and After the TOEIC Course

\begin{tabular}{llllll}
\hline Self-efficacy scores & Mean & $\mathrm{N}$ & $\begin{array}{l}\text { Std. } \\
\text { Deviation }\end{array}$ & $\begin{array}{l}\text { Std. Error } \\
\text { Mean }\end{array}$ & Sig. (2-tailed) \\
\hline before & 2.1330 & 94 & .59293 & .06116 & \multirow{2}{*}{.000} \\
\hline after & 2.5226 & 94 & .46761 & .04823 & \\
\hline
\end{tabular}

Table 3

Descriptive Statistics

\begin{tabular}{llll}
\hline & Mean & Std. Deviation & N \\
\hline Self-efficacy & 2.5226 & .46761 & 94 \\
\hline TOEIC score & 276.06 & 26.618 & 94 \\
\hline
\end{tabular}


Table 4

Correlations

\begin{tabular}{llll}
\hline & & TOEIC Score & Self-efficacy \\
\hline \multirow{3}{*}{ Self-efficacy } & Pearson Correlation & 1 & $.244^{*}$ \\
\cline { 2 - 4 } & Sig. (2-tailed) & 94 & .018 \\
\cline { 2 - 4 } & $\mathrm{N}$ & $.244^{*}$ & 94 \\
\hline \multirow{3}{*}{ TOEIC Score } & Pearson Correlation & .018 & 1 \\
\cline { 2 - 4 } & Sig. (2-tailed) & 94 & 94 \\
\cline { 2 - 4 } & $\mathrm{N}$ & 94 &
\end{tabular}

* Correlation is significant at the 0.05 level (2-tailed).

\section{Sources of self-efficacy information}

Quantitative data show that students' self-efficacy rose moderately after the TOEIC preparation course. Data from focus group discussions with participants make clear that four sources of self-efficacy postulated by Bandura (1997) appeared to inform the participating students' self-efficacy. Findings suggested that mastery experiences appeared to be the most influential source of TOEIC self-efficacy, social persuasion and vicarious experiences also played an important role in forming students' TOEIC selfefficacy.

Mastery experiences: When being asked which sources of information affected their self-efficacy beliefs the most, all participants in 4 groups mentioned mastery experiences. They discussed more examples of enactive and cognitive mastery experiences as sources that influenced their self-efficacy. In terms of cognitive mastery experiences, students reported to gain "better understanding of complex grammatical structures" and "test taking tips" or to enrich their vocabulary and grammar structure resources owing to teachers' lectures and explanations. Strengthen knowledge gradually built up students' self-efficacy beliefs. Many students said that they, after the course, could "tell the differences among many kinds of TOEIC questions", which were important in a test and which they knew little before the course. Regarding enactive mastery experiences, some students reported improved scores of listening or reading tasks as a source which helped them judge their learning ability positively. They said since they "got better scores", they "felt more confident" and "kept working hard for next time". However, several students reported consistent problems with part 3 and part 4 of the listening test or the last section of part 7 of the reading test, e.g. "unable to understand long talks owing to a large number of vocabulary", "difficult to connect information between 2 related texts". These challenges shook their self-efficacy since they rarely got correct answers for those questions.

Social persuasion: This source of self-efficacy information was ranked second by participants in the study. Teachers' words of appreciation, feedback and evaluation, and friends' requests for advice as different forms of social persuasion informed some students whether they were making learning progress. Some students stated that teachers were "very generous", "encouraging" and regularly recognized their effort inside or outside class, both directly and indirectly. For example, participating students reported 
to hear encouraging sentences such as "You must have learnt very hard last night", "Oh, I'm surprised at your work!", "I believe you can pass the test with good results". Many students stated that positive feedback provided by the teachers strengthened both their willingness to practice and their beliefs in their learning ability. Other students stated that "timely feedback" provided weekly throughout the semester by the teachers informed them whether they were "on the right track", thus encouraging them to spend more time practicing. One student say:

When the teacher criticizes me, I think there is still much space for improvement. The teacher pushes me to work harder.

Some students who had problems with listening skills raised the need to study with native English-speaking teachers in order to learn the language authentically. They stressed that "getting familiar with native English speakers' accents will help us much in listening tests". They also noted that "extended class hours in order to get more intellectual support from the teachers" would possibly help them feel more confident in the test. Social persuasion in the form of lack of coaching and mentoring (TschannenMoran \& McMaster, 2009) lowered these students' self-efficacy beliefs.

Vicarious experiences: This particular source of self-efficacy information was ranked $3^{\text {rd }}$ among other sources by participants in the study. Watching their friends doing the tasks or listening to them sharing experiences, that is, being exposed to "competent models" fostered the students' beliefs in their own abilities to work hard to achieve the same achievements or to improve their own performance. A student said: "My friends helped me understand types of questions and important grammatical structures. Her feedback was very helpful". Another said: "Watching others do well motivates me to work harder, because I really want to be as good as them". Self-efficacy in doing the TOEIC test was also influenced by vicarious experiences in the form of searching for test taking tips from the Web or from previous test takers. Many students reported their improved selfefficacy after their TOEIC knowledge and test skills were enriched.

Affective states: Participants did not consider affective states as an important source of self-efficacy information since it was ranked $4^{\text {th }}$. Data also showed that participants' perceptions of their successful/unsuccessful performances (mastery experiences), perceptions of others' feedback and support (social persuasion), and perceptions of comparing their ability with others resulted in their negative or positive feelings. For example, the positive feedback from teachers and friends induced positive feelings, which was a signal of a stronger sense of competence among the students. The students reported that teachers' positive feedback created a feeling of "happiness" and "excitement", and contributed to a higher sense of self-efficacy since the students felt "motivated to learn inside and outside the classroom" or "rewarded for hard work and effort". Besides, some students reported safe feeling since they thought they had something to prepare for the tests after collecting some tips from the Web or previous test takers. 


\section{DISCUSSION}

\section{Students' self-efficacy at the end of the TOEIC preparation course}

In the present study, the finding that students' self-efficacy increased at the end of the TOEIC course which was designed to promote their test skills and practice is similar to what other self-efficacy researchers found in different domains. For example, Moreno and Kilpatrick (2018), relying on design-based research, explored the effects of increased practice and exposure to Italian on student self-efficacy and concluded that increased practice does lead to a higher degree of self-efficacy in the practiced tasks. Students in the study connected practice to their belief of improved abilities. Ainscough et al. (2016) examined the changes in biology self-efficacy during a first-year course of 640 biology students. They discovered that self-efficacy improved from the beginning to the end of the semester. However, in the present study, a closer look at the figures show that students' self-efficacy was at a low level although they were up. Qualitative data show that most students stated that their TOEIC self-efficacy dropped as the test became more challenging. This is probably because student participants were at introductory level aiming at 250 scores; however, the TOEIC mock tests were commercial ones used for test takers at all three levels: introductory, intermediate and advanced. In addition, in most studies in the self-efficacy literature where students had significantly higher sense of self-efficacy beliefs, they were exposed to longer learning hours and extensive practice. For example, in the studies of Moreno and Kilpatrick (2018), students joined in different activities including online instruction and in-class practice and language production in 3 semesters. Due to time and curriculum constraints, the available face-toface instruction is limited to 3 hours a week in 15 weeks, making difficult for the student participants in the present study to understand and master the required knowledge and skills for the TOEIC test. Since increased practice and exposure strengthen self-efficacy in the practiced tasks (Bandura, 1997), practice and learning time currently designed for TOEIC students at the local university should be reviewed.

\section{Relationship between students' self-efficacy beliefs and their TOEIC scores}

In this study, students' self-efficacy predicted their TOEIC performance which is in line with results of previous studies. Regardless of age, gender, domains, disciplines and countries, a student with higher sense of self-efficacy will possibly achieve better academic performance. Boakye (2015) conducted a study with first-year students in a South African tertiary institution to determine the relationship between self-efficacy and reading proficiency. The study showed that self-efficacy is positively and significantly correlated with reading proficiency for this group of students. Similarly, Tilfarlioğlu and Ciftci (2011), Nariman-Jahan and Rahimpour (2010) agreed that self-efficacy is the antecedent in the relationship and exerts a positive influence on performance. Researchers such as Bandura (2007) and Wyatt (2014) highlighted that students with a higher sense of self-efficacy are likely to invest more effort to learning, set them challenging goals to which they are strongly committed and get better achievements. Bandura (2007) suggested that it is then necessary to engender self-efficacy beliefs in students in order to help them achieve better learning performance. One important and 
effective way to do so is to figure out which sources of self-efficacy information are important to the students. The impact on these sources of self-efficacy information may then help to improve students' TOEIC achievements (see below).

\section{Sources of self-efficacy information}

The finding that mastery experiences were the most powerful source of self-efficacy beliefs correlates with findings of previous studies (e.g. Morris (2010); Morris \& Usher (2011); Tschannen-Moran \& McMaster (2009). It appears that social persuasion and vicarious experiences also provided useful points of reference for interpreting selfefficacy information for the participating students. The students' perceptions of their previous learning achievement, others' feedbacks and comparison with their friends seemed to affect their TOEIC self-efficacy beliefs, which, in turn, influenced their TOEIC achievements. This suggests that by targeting these three sources of selfefficacy, especially mastery experiences, teachers can empower students with control over their own TOEIC ability development. Several implications for educators involved in the development and implementation of student TOEIC courses are presented below.

In relation to mastery experiences, findings show that successful learning experiences boosted students' self-efficacy and that participating students expressed their needs to get more knowledge of complex grammatical constructions and difficult vocabulary in order to improve their self-efficacy beliefs. Therefore, it is important to provide students with successful learning experiences. Together with the increasing number of practice and learning hours (see above), how TOEIC knowledge and skills are presented to students is also crucial. Brown (2006, pp. 22-25) listed a range of activities that can be practical for lower-level students and that local teachers might want to include into their lesson plans. Activities should be planned in a way that it could help students to reinforce their prior grammatical knowledge and to instil positive experience of accomplishing tasks. Activities should be given progressively and gradually in order to develop strong students' efficacious beliefs. Student participants' listening skills will possibly be improved if they are exposed to different accents and a range of listening tasks systematically, which is linked to students' need to have native English speaking teachers. At the university where the study was conducted, it is unlikely that more native English speaking teachers will be recruited to satisfy students' need due to low budget. Therefore, it all depends on teachers' designed activities to include as many accents as possible in the listening tasks so as to give students more opportunities to apply their new knowledge in a different context. At present, with the help of Internet and web tools, this task is manageable as long as teachers are committed to students and their learning.

In terms of cognitive mastery experiences, students in the study expressed their hope for extended class hours in order to get more intellectual support from the teachers in class and to develop TOEIC test skills and knowledge. The global trend now is a focus on improving existing learning time rather than using an extending time model. It is clear that the amount of instructional time is not so important as how that time is spent (Joyner \& Molina, 2012). With a decreased number of class periods per day, teachers should think of opportunities to implement creative teaching strategies to meet the needs 
of students and have more one-to-one time for interactions with students in class. An example of implement creative teaching strategies is to flip the classroom to optimize instructional time (Bergmann \& Sams, 2012; Moreno \& Kilpatrick, 2018). Flipped classrooms are known as to create a community learning inside and outside the classroom without using too much class learning time since students practice lowerorder skills such as information gathering and memorization at home prior to class.

Regarding social persuasion, teacher support and feedback in the present study were important factors in encouraging the development and maintenance of student selfefficacy, which is in line with results of previous studies (e.g., Mitchell \& DellaMattera, 2010; Schmidt \& Shumow, 2012). Once teachers focus on elaborating, fostering thinking and questioning students, frequent meaningful conversations are created to promote students' successful learning experiences. Teacher feedback should be understandable and specific, that is, linked to the task and criteria in order to enhance students' beliefs in their competence relating to TOEIC knowledge.

In the present study, peer feedback also contributed positive information to students' self-efficacy beliefs. In academic literature, peer modeling has been considered as one helpful way among others to promote students' self-efficacy (Meera \& Jumana, 2016; Moreno and Kilpatrick, 2018) since it helps to create comfort, decrease anxiety and promote production. Moreno and Kilpatrick (2018) recommended long-term relationships and the development of mini cohorts within large classes to build positive relationship among students. In order to reduce over-reliance on partner-pairing activities, teachers and educators might want to distribute different roles among groups of students throughout the semester or school year. Falout (2004) recommended practicing TOEIC learning strategies with partners communicatively, which he argued can help students orient cognitive learning processes. Students can know what features to emphasize and gauge their progress from hearing partners' immediate feedback and seeing their reactions.

\section{CONCLUSION}

While there is much research connecting self-efficacy to increased language proficiency, it has been noted that little research focuses on how to develop efficacy (Edwards and Roger, 2015; Raoofi, Tan, \& Chan, 2012) in general and TOEIC self-efficacy in particular. Previous studies also provide little information on the self-efficacy beliefs of EFL participants from East Asian contexts. The present study helped to understand changes in Vietnamese students' self-efficacy after the end of the TOEIC preparation course, the relationship between self-efficacy and TOEIC achievement and sources of self-efficacy information. Findings indicated that students' self-efficacy improved moderately after the course. There was a positive relationship between students' selfefficacy and their TOEIC achievement and mastery experiences were the most powerful source of self-efficacy. This research has the potential to inform TOEIC preparation courses in Vietnam and in similar settings.

Given the design of this study, it is not without limitations. The mock tests used in this study were the TOEIC tests which were publicized by ETS. It is possible that some 
students had even done the same tests before so that the scores were not accurate. In order to have a more accurate comparison, the official TOEIC test should be used in future studies. The participating pool with only 94 students was rather small. To ensure meaningful results, larger sample sizes are preferable. In addition, there were no control groups being manipulated in the present study. Therefore, generalizing the results to a wider EFL context, e.g. the whole TOEIC learners in Vietnam as a population, should be careful. To further test the change in students' self-efficacy, an experimental study encompasses both the control and the experiment group is called for. In addition, future researchers may want to compare students' listening self-efficacy beliefs with reading self-efficacy beliefs. Longitudinal research will also be necessary to strengthen the conclusions drawn here. Since relatively few studies have looked at TOEIC self-efficacy and sources of TOEIC self-efficacy, future research on these issues is desirable.

\section{REFERENCES}

Ainscough, L., Foulis, E., Colthrope, K., Zimbardi, K., Robertson-Dean, M., Chunduri, P., \& Lluka, L. (2016) Changes in biology self-efficacy during a first-year university course. CBE Life Sci Educ., 15(2). doi: 10.1187/cbe.15-04-0092.

Bandura, A. (1997). Self-efficacy: The exercise of control. New York: Freeman.

Bandura, A. (2006). Toward a psychology of human agency. Perspectives on psychological science, 1(2), 164-180. doi: 10.1111/j.1745-6916.2006.00011.x.

Bergmann, J., \& Sams, A. (2012). Flip your classroom: Reach every student in every class every day. Washington, DC: ISTE; and Alexandria, VA: ASCD.

Boakye, N. A. N. Y. (2015). The relationship between self-efficacy and reading proficiency of first-year students: An exploratory study. Reading \& Writing, 6(1), 1-9. doi: $10.4102 /$ rw.v6i1.52.

Bong, M. (2006). Asking the right question: How confident are you that you could successfully perform these tasks? In F. Pajares, \& T. Urdan (Eds.), Self-efficacy beliefs of adolescents (pp. 287-305). Greenwich, CT: Information Age Publishing.

Braun, V., \& Clarke, V. (2006). Using thematic analysis in psychology. Qualitative Research in Psychology, 3(2), 77-101. doi: 10.1191/1478088706qp063oa.

Brown, H. (2006). Learner perceptions of TOEIC test results and language skill improvements: "I don't want to study English, I want to study TOEIC". In K. BradfordWatts, C. Ikeguchi, \& M. Swanson (Eds.) JALT2005 Conference Proceedings. Tokyo: JALT.

Burrows, L. P. (2016). Retrospective and current levels of self-efficacy in Japanese learners. Indonesian J of Applied Linguistics, 6(1), 30-41. doi: 10.17509/ijal.v6i1.2659.

Chen, H. Y. (2007). The relationship between EFL learners' self-efficacy beliefs and English performance (Unpublished doctoral dissertation). Florida State U., Florida. 
Childs, M. ( 2002) . What you can expect from TOEIC preparation. The Daily Yomiuri. Oct. 18: 18. $\quad$ Retrieved from https://db.yomiuri.co.jp/dpscripts/DpDetail.dll?Detail.

Cho, M. H., \& Shen, D. (2013). Self-regulation in online learning. Distance Educ. 34, 290-301. doi: 10.1080/01587919.2013.835770.

Creswell, J. W. (2012). Educational research: planning, conducting, and evaluating quantitative and qualitative research. Boston: Pearson

Edwards, E., \& Roger, P. S. (2015). Seeking out challenges to develop L2 selfconfidence: A language learner's journey to proficiency. TESL-EJ, 18(4), 1-24.

ETS (2015). Examinee handbook: Listening and reading. Retrieved from https://www.ets.org/s/toeic/pdf/listening-reading-examinee-handbook.pdf.

Fallout, J. J. (2004). Focused tasks to proceduralize TOEIC learning strategies. The interface between interlanguage, pragmatics and assessment: Proceedings of the May 22 -23 JALT Pan-Sig conference (pp. 38 - 44), Tokyo Keizan University, Tokyo, Japan.

Gębka, B. (2014). Psychological determinants of university students' academic performance: an empirical study. J. Further High. Educ, 38, 813-837. doi: 10.1080/0309877X.2013.765945.

Gedds, A. J. (2016). Korean university students' attitudes and motivation towards studying English. Universal Journal of Educational Research, 4(4),704-715.

Genç, G., Kuluşaklı, E., \& Aydın, S. (2016). Exploring EFL learners' perceived selfefficacy and beliefs on English language learning. Australian Journal of Teacher Education, 41(2). doi: 10.14221/ajte.2016v41n2.4.

Harada, S. (2016). Effects of the TOEIC course on students' TOEIC scores. The Bulletin of St. Margaret's, 48, 1-17.

Honicke, T., \& Broadbent, J. (2016). The influence of academic self-efficacy on academic performance: A systematic review. Educational Research Review, 17, 63-84. doi: 10.1016/j.edurev.2015.11.002.

Hsieh, C-N (2017). The case of Taiwan: Perceptions of college students about the use of the TOEIC Tests as a condition of graduation, ETS Research Report Series, 1, 1-12. doi: 10.1002/ets2.12179.

Iaochite, R. T., \& Souza N, S. (2014). Strength and sources of self-efficacy beliefs by physical education student teachers. Motriz: Revista de Educação Física, 20(2), 143150. doi: 10.1590/S1980-65742014000200003.

Joyner, S., \& Molina, C. (January, 2012). Class time and student learning. Retrieved from http://www.sedl.org/txcc/resources/briefs/number6/. 
Leedy, P. D., \& Ormrod, E. J. (2005). Practical research: Planning and design. Upper Saddle River, NJ: Pearson Education.

Loo, C. W., \& Choy J. L. F. (2013), Sources of self-efficacy influencing academic performance of engineering students, American Journal of Educational Research, 1(3), 86-92. doi: 10.12691/education-1-3-4.

Klassen, R. M., \& Usher, E. L. (2010). Self-efficacy in educational settings: Recent research and emerging directions. In S. A. K. Timothy, \& C. Urdan (Ed.), The decade ahead: Theoretical perspectives on motivation and achievement (Vol. 16). UK: Emerald Group Publishing Limited.

Marshall, C., \& Rossman, G. B. (2011). Designing qualitative research. Thousand Oaks, CA: Sage.

Meera, K. P., \& Jumana, M. K., (2016). Self-efficacy and academics performance in English. Imperial Journal of Interdisciplinary Research, 2(2), 79-83.

Meral, M., Colak, E., \& Zereyak, E. (2012). The relationship between self-efficacy and academic performance. Procedia - Social and Behavioral Sciences, 46, 1143- 1146, doi: 10.1016/j.sbspro.2012.05.264.

Mitchell, S. N., \& DellaMattera, J. N. (2010). Teacher support and student's selfefficacy beliefs. Journal of Contemporary Issues in Education, 5(2), 24-35.

Moreno, R., \& Kilpatrick, J. (2018). Student perceptions of self-efficacy in the foreign language classroom: A design-based research study. Educational Design Research, 2 (1), 1-26. doi: 10.15460/eder.2.1.1214.

Morris, D. B. (2010). Sources of award-winning professors' self-efficacy: A qualitative investigation (Unpublished doctoral dissertation). Emory University, Atlanta, GA.

Morris, D. B., \& Usher, E. L. (2011). Developing teaching self-efficacy in research institutions: A study of award-winning professors. Contemporary Educational Psychology, 36(3), 232-245. doi: 10.1016/j.cedpsych.2010.10.005.

Oh, H. J. (2012). The relationship between self-efficacy and TOEIC achievement. English Language Teaching. 24(3), 299 - 319.

Palmer, D. (2006). Sources of self-efficacy in a Science methods course for primary teacher education students. Research in Science Education, 36(4), 337-353. doi: $10.1007 / \mathrm{s} 11165-005-9007-0$

Palmer, D. (2011). Sources of efficacy information in an inservice program for elementary teachers. Science Education, 95(4), 577-600. doi: 10.1002/sce.20434. 
Phan, N. T. T., Locke, T. (2016) "Vietnamese teachers' self-efficacy in teaching English as a Foreign Language: Does culture matter?", English Teaching: Practice \& Critique, 15(1), 105-128. doi: 10.1108/ETPC-04-2015-0033.

Rahimpour, M., \& Nariman-jahan, R. (2010). The influence of self-efficacy and proficiency on EFL learners' writing. J of Inst Tech and Distance Learn, 7(11), 23-36.

Raoof, S., Tan, B. H., \& Chan, S. H. (2012). Self-efficacy in second/foreign language learning contexts. English Language Teaching, 5(11), 60-73.

Schmidt, J. A., \& Shumow, L. (2012). Change in self-efficacy in high school science classrooms: An analysis by gender. In S. L. Britner (Ed.), Psychology of self-efficacy (pp. 53-74). Hauppauge, New York: Nova Science Publishers.

Schunk, D. H., Pintrich, P. R., \& Meece, J. L. (2008). Motivation in education: Theory, research, and applications. Upper Saddle River, N.J: Merrill.

Siriparp, T. (2015), Examining self-efficacy and achievement in an educational research course. ProcSocBehav Sci., 171, 1360-1364. doi: 10.1016/j.sbspro.2015.01.254.

Taguchi, K. (2015). An exploratory study on correlations among vocabulary size, vocabulary learning strategy use,TOEIC scores and self-efficacy. The Economic Review of Toyo University, 41(1), 55-67.

Talsma, K., Schüz, B., Schwarzer, R., \& Norris, K. (2018), I believe, therefore I achieve (and vice versa): A meta-analytic cross-lagged panel analysis of self-efficacy and academic performance. LearnIndivid Differ., 61,136-150.

Thomas, A. (2008). Focus groups in qualitative research: culturally sensitive methodology for the Arabian Gulf? International Journal of Research \& Method in Education, 31(1), 77-88. doi: 10.1080/17437270801919941.

Tilfarlioğlu, F. T., \& Ciftci, F. S. (2011). Supporting self-efficacy and learner autonomy in relation to academic success in EFL Classrooms (A case study). Theory and Practice in Language Studies, 1(10), 1284-1294. doi: 10.4304/tpls.1.10.1284-1294.

Todaka, Y. (2016). Self-efficacy of English listening skills in Japanese college EFL learners. Int J of Edu \& Pra, 4(1), 21-36. doi: 10.18488/journal.61/2016.4.1/61.1.21.36.

Toyama, M. (2015). Self-efficacy, e-learning and online efl proficiency test. The Asian Conference on Psychology \& the Behavioral Sciences 2015. Official Conference Proceedings. Retrieved from https://acp.iafor.org/acp2015/

Tran, T. N. (2006). Discovering the identity of Vietnamese culture: Typologicalsystematic views (Tim ve ban sac van hoa Viet nam: Cai nhin he thong-loai hinh). Ho Chi Minh City: Ho Chi Minh City Press. 
Tschannen-Moran, M., \& McMaster, P. (2009). Sources of self-efficacy: Four professional development formats and their relationship to self-efficacy and implementation of a new teaching strategy. The Elementary School Journal, 110(2), 228-245. doi: 10.1086/605771.

Tschannen-Moran, M., Hoy, A. W., \& Hoy, W. K. (1998). Teacher efficacy: Its meaning and measure. Re of Edu Res, 68(2), 202. doi: 10.3102/00346543068002202.

Usher, E. L., \& Pajares, F. (2008). Sources of self-efficacy in school: Critical review of the literature and future directions. Review of Educational Research, 78(4), 751-796. doi: $10.3102 / 0034654308321456$.

Wheatley, K. F. (2005). The case for reconceptualizing teacher efficacy research. Teaching and Teacher Education, 21(7), 747-766. doi: 10.1016/j.tate.2005.05.009.

Wyatt, M. (2014). Towards a re-conceptualization of teachers' self-efficacy beliefs: tackling enduring problems with the quantitative research and moving on. International Journal of Research \& Method in Education, 37(2), 1-24.

Zhang, \& Ardasheva, Y. (2019). Sources of college EFL learners' self-efficacy in the English public speaking domain. English for Specific Purposes, 53, 47-59. 